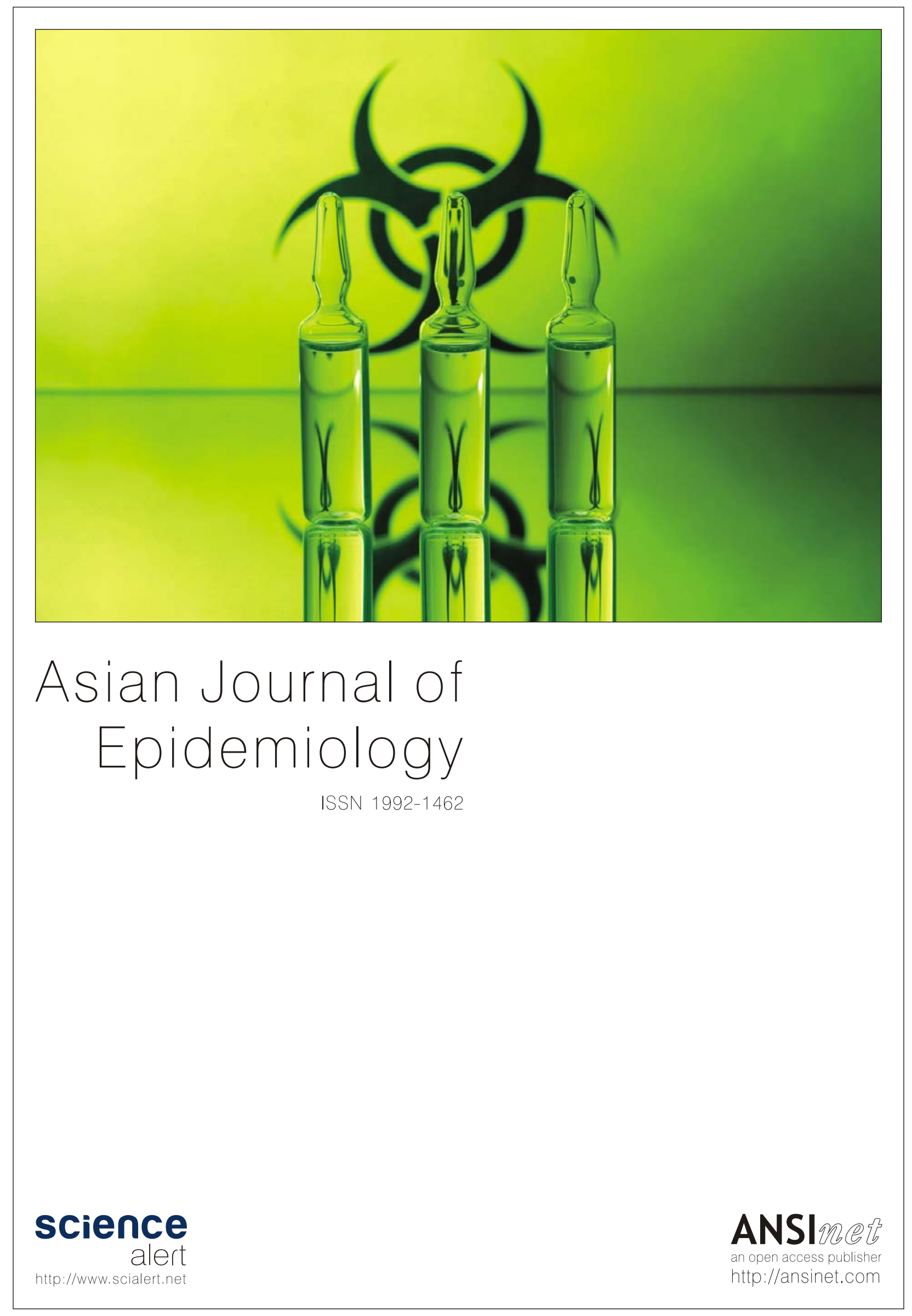




\title{
Risk of Exposure to Soil-transmitted Helminths in the Zoological Garden in Southwestern Nigeria
}

\author{
Oyebamiji David A., Olabode Ifeoluwa and Hassan Adesola A. \\ Parasitology Unit, Department of Zoology, Faculty of Science, University of Ibadan, Nigeria
}

\section{Abstract}

Background and Objective: Poor hygienic practices are associated with the transmission of zoonotic organisms and risk of infection is high among children and other high risk group in close proximity to animals especially those in captives like the Zoos. This study was designed to assess the possibility of exposure to Soil-Transmitted Helminths (STH) that may be acquired from animals around the Zoological Garden. Materials and Methods: Soil samples were collected from 13 different locations around the Zoological Garden between June and August, 2017. The collected samples were examined for the presence of parasites' eggs/larvae using modified Baermann technique and simple floatation technique. Different questionnaires were administered to the zookeepers and visitors of the zoo to obtain information on the eating and hand washing behaviours as well as other risk related activities carried out in the garden. Results: Out of the 156 samples collected there was a contamination rate of $98.7 \%$. The STH egg/larvae load recorded per $10 \mathrm{~g}$ of soil were Ascaris (541), hookworm (1161) and Strongyloides (863). The main dumping site had the highest intensity of parasites out of the 13 locations. Questionnaires administered showed that $56 \%$ of zookeepers displayed good hand washing habits and $63.4 \%$ of visitors also displayed good hand washing habits. A total of 101 (80.8\%) visitors to the Zoo Garden ate in the garden out of which 36.6\% did not wash their hands before eating. Conclusion: Prevalence and intensity of STH observed in the Zoological Garden was significantly high posing a risk of STH transmission to people. Therefore, there is a need for adequate intervention and regular health talks to sensitize visitors particularly to the risk of exposure to zoonotic organisms.

Key words: Zoological garden, zoonotic, poor hygienic practices, zookeepers, hand washing behaviours, captive wild

Citation: Oyebamiji David A., Olabode Ifeoluwa and Hassan Adesola A., 2019. Risk of exposure to soil-transmitted helminths in the zoological garden in Southwestern Nigeria. Asian J. Epidemiol., 12: 17-24.

Corresponding Author: Oyebamiji David A., Parasitology Unit, Department of Zoology, Faculty of Science, University of Ibadan, Ibadan, Oyo State, Nigeria Tel: +23438035783607

Copyright: @ 2019 Oyebamiji David A. et al. This is an open access article distributed under the terms of the creative commons attribution License, which permits unrestricted use, distribution and reproduction in any medium, provided the original author and source are credited.

Competing Interest: The authors have declared that no competing interest exists.

Data Availability: All relevant data are within the paper and its supporting information files. 


\section{INTRODUCTION}

Soil Transmitted Helminths (STHs) including hookworms (Necator americanus and Ancylostoma duodenale), roundworms (Ascaris lumbricoides) and whipworms (Trichuris trichuira) impose a substantial burden of disease'. It has been estimated that 819 million people are infected with A. lumbricoides, 465 million with $T$. trichiura and 439 million with hookworms globally ${ }^{2}$. In 2010, a total of 2,824 estimated deaths were attributed to $A$. lumbricoides and there were no deaths attributed to hookworm and T. trichiura ${ }^{2}$. About 4.98 million people lived with disability attributed to STH of which $65 \%$ resulted from hookworm, $22 \%$ from $A$. lumbricoides and the remaining $13 \%$ from $T$. trichiura ${ }^{2}$.

A number of studies have suggested that even a moderate intensity of STH infection may result in delayed physical growth and impaired cognitive development, particularly among children of school-age and STH infections are considered a leading cause of sickness, absenteeism and disability ${ }^{3,4}$. Children are more affected than adults because they are still in the growth and developmental stages.

Humans are generally exposed to many parasites in the environment and some may be of zoonotic origins. Such exposure can cause several health problems. The zoonotic diseases are of particular risk to those who encounter animals in the course of discharging their duties as animal handlers or keeping animals as pets. Many parasites like Ancylostoma caninum, Toxocara canis may cause these zoonotic diseases ${ }^{5}$.

School children form the bulk of visitors to public places like Zoological Garden. Children are known to play with soil, eat with unwashed hands if they are not well monitored hence the need for Zoos to put proper safety measures in place. Many studies have been performed to evaluate the contamination of soil with parasites in public places especially parks and children playground in different cities and results are varied due to environmental factors, cultural differences and so on ${ }^{5}$.

Some studies have revealed that gastrointestinal parasites of wild animals in captivity have zoonotic potentials and this raises public health concerns ${ }^{6,7}$. A study carried out in Calabar showed that $70 \%$ of the primates examined for gastrointestinal parasites harboured several parasites of zoonotic importance ${ }^{8}$. Visitors to the zoo and zookeepers can be at high risk of exposure to parasites if standard safety measures are neglected. Such safety measures as the provision of hand sanitizing points, prevention of eating and selling food items within the garden, not picking the soil, special dress code for zookeepers (overall, rain boots, hand gloves) which should be properly washed after caring for animals. Most times, animal keepers disregard safety tips and when this happens there is a higher risk of exposure to infective agents.

Soils are the most common source and reservoir of parasite eggs, infective larvae, cysts and oocysts, which may continue their life cycle, as they remain viable in the soil for months or even years until ingestion occurs ${ }^{5}$. There are risks of humans being infected or exposed to these helminths in the soil. This can occur by ingestion of contaminated soil or by active penetration of larval stage through the skin ${ }^{9}$. The risk of exposure to STH is inextricably linked with water quality, sanitation, hygiene practices and socio-economic status of each individual ${ }^{4}$.

Therefore, this study was carried out to determine the prevalence and risk of exposure to humans', the soiltransmitted helminths in the soil especially when people are at risk of exposure in public recreational facilities where animals are kept.

\section{MATERIALS AND METHODS}

Study area and location: Study was carried out in Ibadan which is located in the south-western part of Nigeria $128 \mathrm{~km}$ inland northeast of Lagos and $530 \mathrm{~km}$ southwest of Abuja. It lies within latitude $7^{\circ} 19^{\prime} 08^{\prime \prime}$ and $7^{\circ} 29^{\prime} 25^{\prime \prime}$ of the equator and longitude $3^{\circ} 47^{\prime} 50^{\prime \prime}$ and $4^{\circ} 0^{\prime} 22^{\prime \prime}$ completely within the tropical forest zone. It has a tropical wet and dry climate with a lengthy wet season and relatively constant temperatures throughout the course of the year ${ }^{10}$. The study location was the Zoological Garden of the University of Ibadan. University of Ibadan is located five miles $(8 \mathrm{~km}$ ) from the centre of the major city of Ibadan, Oyo state in the Western part of Nigeria ${ }^{11}$. The Zoological Garden came into existence over 6 decades ago and became a full-fledged zoo in 1974. It is mainly for conservation, education and entertainment purposes. Animals are grouped in different sections of the zoo; Avian, Herbivore, Carnivore, Reptile, Primate and small animal sections.

Study site: Soil samples were collected from 13 sites within the entire garden, the sites were picked randomly across the different sections and designated as indicated below; Playground $(\mathrm{Pg})$, Food and drink store ( $\mathrm{Fds})$, Monkey cages $(\mathrm{Mc})$, Bird cages $(\mathrm{BC})$, Camel cage $(\mathrm{Cc})$, Emu cage (Ec,) Jackal cage (Jc), Rodent cage (Rc), Giant e-land and Giraffe (G.G), Horse cage $(\mathrm{Hc})$, Peacock cage $(\mathrm{Pc})$, Dumping site within the garden (Ds1) and Dumping site outside the garden (Ds2). 
Sample size determination and sampling design: Sample size was calculated according to the formula by $\mid$ Israel $^{122}$ :

$$
\mathrm{n}_{\mathrm{o}}=\left(\mathrm{Z}^{2} \mathrm{pq}\right) / \mathrm{e}^{2}
$$

Minimum soil sample size: $\left(1.96^{2} \times 0.5 \times 0.5\right) / 0.08^{2}=150$

A total of 156 soil samples were collected from June-August, 2017. Four replicate samples were taken from each of the 13 sampling sites every month.

Study participants and sample size determination: All the zookeepers and a sample of visitors to the zoo were included in the assessment of risk factors associated with exposure to soil STHs. There were no age or sex biases for participating. Selection was done based on simple random sampling. This sample size was obtained using the formula by Israel ${ }^{12}$.

Minimum sample size for the visitors to the zoo $\left(\mathrm{n}_{\mathrm{o}}\right)=\left(\mathrm{Z}^{2} \mathrm{pq}\right) / \mathrm{e}^{2}$ $\left(1.96^{2} \times 0.5 \times 0.5\right) / 0.09^{2}=120$

Questionnaire administration: Two different questionnaires, QA and $Q B$ were designed and pre-tested for the rapid assessment of standard practices on eating and hand washing behavior around the Zoological Garden to establish possible risk of transmission of soil-transmitted helminths in the area. The QA was administered to all the 25 zoo keepers in the garden to obtain information on the sex, eating and hand washing behaviors as well as the cleaning procedures carried out in the garden, while QB was administered to a sample of visitors in the garden (125) to obtain information on age, sex, educational status and personal hygiene.

Soil sample collection: Soil samples were collected using a hand trowel at the depth of 3-7 $\mathrm{cm}$ which was then stored in a well labeled polythene as recommended by Nooraldeen ${ }^{5}$. This was taken to the laboratory for further examination.

Laboratory examination of soil samples: Modified Baermann method: Materials used for this modified baermann method included, plastic bottles that was cut into two for use as an improvised funnel, cloth mesh net, tissue paper in place of filter paper, rubber bands, Petri dishes and water. A teaspoon full of soil (10 g) was placed on the tissue wrapped up in the cloth mesh net that was cut out in pieces at an area of about $25 \mathrm{~cm}^{2}$, this was properly tied using the rubber band and it was attached to the funnel shaped bottle on the stand using rubber band. Water was added to the funnel shaped bottle containing the soil. This set up was left for $48 \mathrm{~h}$ to allow for the migration of the larval into the water. After $48 \mathrm{~h}$, the larval would have settled at the base of the collection bottle water. The supernatant was gently decanted and the sediment was poured into a Petri dish and was observed under the microscope $\mathrm{e}^{13,14}$. Floatation technique described by Timothy et al. ${ }^{15}$ was also used.

\section{Identification and counting of larvae and ova of STHs}

Microscopy: Using x 10 objective, recovered eggs and larvae were counted systematically from each of the soil samples examined this was immediately recorded in a record book. An atlas of medical parasitology by Rai et al. ${ }^{16}$ was used as a guideline in identification of larva and ova.

Statistical analysis: The data was analyzed using R-console 3.2.3 and chi square at 5\% level of significance to test for the significant difference in the prevalence of the parasite counts in relation to the location. The questionnaire was analyzed using SPSS 20.0 and Chi-square $\left(\chi^{2}\right)$. Significant difference at $p<0.05$ was tested in relation to the intensity of parasites found in each month and per location.

\section{RESULTS}

Overall prevalence of parasites: The parasite species types encountered from the 156 soil sample examined included; Ascaris, Hookworm and Strongyloides. A total of 154 (98.7\%) of the examined soil samples were positive for the infective stages of at least one helminths species. The species specific prevalence of Ascaris, Hookworm and Strongyloides were $82.7,74.4$ and $80.1 \%$, respectively (Table 1 ). There was no significant difference $(p>0.05)$ in the prevalence of each parasite.

Parasites prevalence in relation to sampling sites: In Table 2, the prevalence of parasites in different animal location was shown. The highest prevalence was from soils around the monkey cage and the least prevalence was the dumping site 1 . There was no significant difference $(p>0.05)$ in the prevalence parasite in each of the 3 parasite across all the 13 locations.

Table 1: Prevalence of the different type of soil-transmitted helminths encountered in soil samples

\begin{tabular}{lcc}
\hline Species type & No positive & Positive (\%) \\
\hline Ascaris & 129 & 82.7 \\
Hookworm & 116 & 74.4 \\
Strongyloides & 125 & 80.1 \\
\hline Number examined $=156$ & &
\end{tabular}


Asian J. Epidemiol., 12 (1): 17-24, 2019

Table 2: Prevalence of the different species of soil-transmitted helminth encountered with respect to location

\begin{tabular}{|c|c|c|c|c|c|c|}
\hline \multirow[b]{2}{*}{ Location } & \multicolumn{2}{|l|}{ Ascaris eggs } & \multicolumn{2}{|c|}{ Hookworm larvae } & \multicolumn{2}{|c|}{ Strongyloides larvae } \\
\hline & No Positive & Positive (\%) & No positive & Positive (\%) & No Positive & Positive (\%) \\
\hline$\overline{\text { Bird }}$ & 10 & 83.33 & 10 & 83.33 & 10 & 83.33 \\
\hline Camel & 9 & 75.00 & 10 & 83.33 & 9 & 75.00 \\
\hline Dumping1 & 8 & 66.67 & 9 & 75.00 & 7 & 58.33 \\
\hline Dumping2 & 9 & 75.00 & 9 & 75.00 & 8 & 66.67 \\
\hline F.D.S & 11 & 91.67 & 9 & 75.00 & 11 & 91.67 \\
\hline G.G & 10 & 83.33 & 8 & 66.67 & 8 & 66.67 \\
\hline Horse & 10 & 83.33 & 10 & 83.33 & 9 & 75.00 \\
\hline Jackal & 11 & 91.67 & 8 & 66.67 & 11 & 91.67 \\
\hline Monkey & 10 & 83.33 & 9 & 75.00 & 12 & 100.00 \\
\hline Emu & 12 & 100.00 & 9 & 75.00 & 10 & 83.33 \\
\hline Peacock & 8 & 66.67 & 8 & 66.67 & 10 & 83.33 \\
\hline Play gr & 9 & 75.00 & 9 & 75.00 & 10 & 83.33 \\
\hline Rodent & 12 & 100.00 & 8 & 66.67 & 10 & 83.33 \\
\hline
\end{tabular}

Number examined per site $=12$

Table 3: Intensity of soil transmitted helminths with respect to location

\begin{tabular}{|c|c|c|c|c|}
\hline \multirow[b]{2}{*}{ Location } & \multicolumn{4}{|c|}{ Mean \pm standard error } \\
\hline & Ascaris & Hookworm & Strongyloides & Total \\
\hline Bird cage & $69.00 \pm 22.87$ & $92.00 \pm 16.38$ & $74.00 \pm 12.67$ & $78.33 \pm 6.98$ \\
\hline Camel cage & $60.00 \pm 13.84$ & $72.00 \pm 13.89$ & $54.44 \pm 11.07$ & $57.67 \pm 6.33$ \\
\hline Dumping site 1 & $47.50 \pm 9.21$ & $62.22 \pm 16.65$ & $100.00 \pm 34.37$ & $54.67 \pm 9.23$ \\
\hline Dumping site 2 & $17.78 \pm 2.78$ & $198.16 \pm 30.78$ & $155.00 \pm 40.36$ & $139.00 \pm 75.72$ \\
\hline Food/drink store & $51.82 \pm 20.57$ & $91.11 \pm 9.04$ & $62.73 \pm 13.08$ & $69.33 \pm 7.22$ \\
\hline G.G & $56.00 \pm 12.58$ & $98.75 \pm 6.11$ & $46.25 \pm 8.64$ & $57.33 \pm 12.14$ \\
\hline Horse cage & $28.00 \pm 5.54$ & $68.00 \pm 12.45$ & $55.56 \pm 15.82$ & $48.67 \pm 11.57$ \\
\hline Jackal cage & $33.64 \pm 4.91$ & $81.25 \pm 15.52$ & $52.73 \pm 10.28$ & $53.33 \pm 8.41$ \\
\hline Monkey cage & $29.00 \pm 7.22$ & $114.44 \pm 21.22$ & $66.67 \pm 10.54$ & $70.67 \pm 21.87$ \\
\hline Emu cage & $41.67 \pm 7.67$ & $72.22 \pm 17.38$ & $54.00 \pm 8.97$ & $57.00 \pm 5.13$ \\
\hline Peacock cage & $30.00 \pm 8.86$ & $113.75 \pm 23.89$ & $78.00 \pm 13.15$ & $64.33 \pm 20.51$ \\
\hline Play ground & $24.44 \pm 3.77$ & $63.33 \pm 7.45$ & $46.00 \pm 9.09$ & $41.67 \pm 6.33$ \\
\hline Rodent cage & $50.83 \pm 7.63$ & $67.50 \pm 12.06$ & $74.00 \pm 11.66$ & $63.00 \pm 5.86$ \\
\hline Total & $41.94 \pm 3.36$ & $100.09 \pm 10.04$ & $69.04 \pm 4.82$ & $855.00 \pm 179.0$ \\
\hline$p$-value & $>0.05$ & $<0.05$ & $<0.05$ & $<0.05$ \\
\hline
\end{tabular}

Parasite load in relation to location: Overall highest mean intensity was recorded for Hookworm followed by Strongyloides and the least was Ascaris. At the 13 different locations the mean intensity was only significant for Hookworm and Strongyloides and not significantly different for Ascaris (Table 3). The observed variation in intensity across sites was significant. However, the mean intensity was highest (198.16 \pm 30.78 ) for hookworm at dumping site 2 followed by $155 \pm 40.36$ for Strongyloides at dumping site 2 and $69.00 \pm 22.87$ for Ascaris at bird cages. The mean intensity for each specific parasite ranged from 24.44 $\pm .77-69.00 \pm 22.87$ for Ascaris, hookworm ranged from $62.22 \pm 16.65$ to $198.16 \pm 30.78$ while the mean intensity for Strongyloides ranged from 46.0 $\pm 9.09-155 \pm 40.36$. There was no significant difference in the mean intensities for Ascaris across the sampling sites whereas significant difference was recorded for hookworm and Strongyloides.
Risk of exposure among zookeepers: There were 25 zookeepers who participated in the risk assessment survey; 14 (56\%) were males while 11 (44\%) were females (Fig. 1). About $20 \%$ of the participants use gloves, out of which $21.43 \%$ were male and $18.18 \%$ were female, $80 \%$ reported that they wear protective clothing, this includes $71.43 \%$ males and $90.91 \%$ female. About $28 \%$ of the zookeepers avoid direct contact with the animal, which consists of $35.71 \%$ male and $18.18 \%$ female (Table 4). About $88 \%$ of the zookeepers sweep the cages after feeding the animals, $96 \%$ dispose food remains at the dumping site. Hand washing habits adopted includes $32 \%$ use of water only (32\%), use of soap and water $(56 \%)$, use of wipes (0\%) while use of sanitizers (12\%) (Table 5).

Risk of exposure among zoo visitors: There were 125 consenting individuals enrolled into the study. Among these participants $55.2 \%$ (69) were females while $44.8 \%$ (56) 


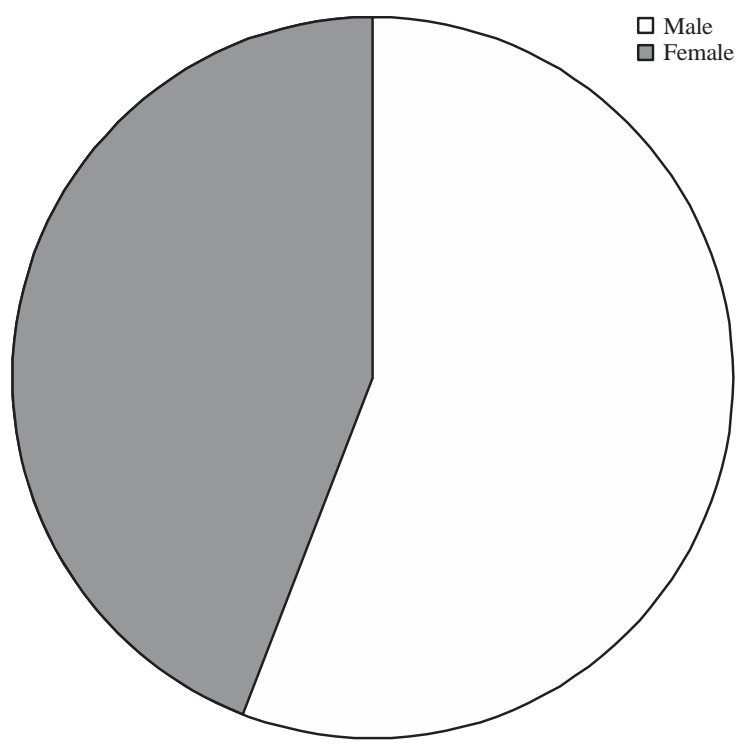

Fig. 1: Percentage of male and female zookeepers

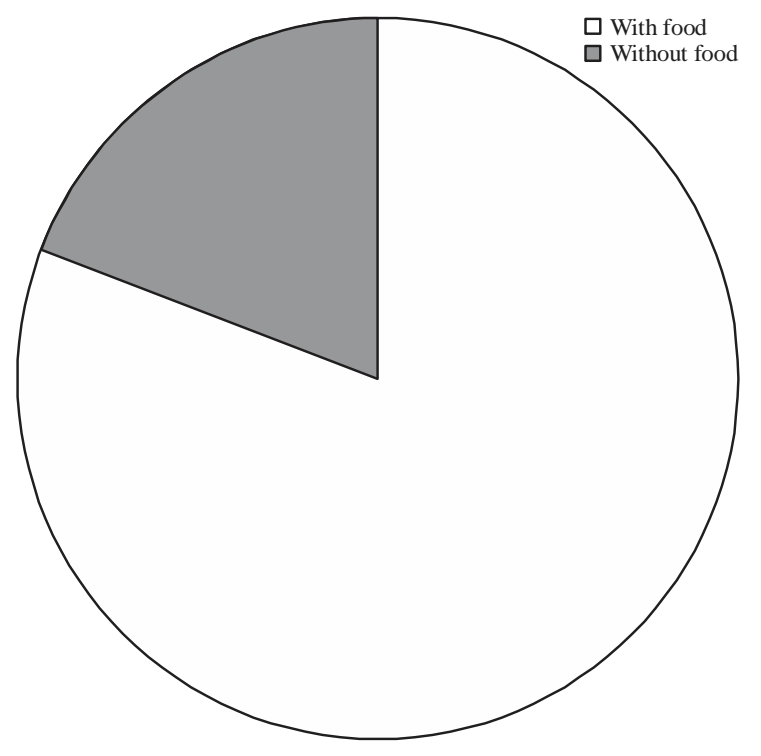

Fig. 2: Proportions with or without food in the Garden

were males. A total of 62 (49.6\%), 28 (22.4\%) and 35 (28.\%) of the visitors enrolled into the study fall into the age category 0-12 years, 13-19years and 20 years above respectively, also out of the 125 respondents, 115 (92.0\%) were students and 10 (8.0\%) were civil servants or Teachers. Figure 2 shows that out of the 125 visitors interviewed, 101 (80.8\%) took food along with them and the remaining 24 (19.2\%) visited the garden without food. Out of the 101 persons that had access to food and or drink while in the garden, 33 (32.7\%) brought food from home while 68 (67.3\%) bought food in the garden (Fig. 3). Figure 4 shows that, out of the 101 persons that had

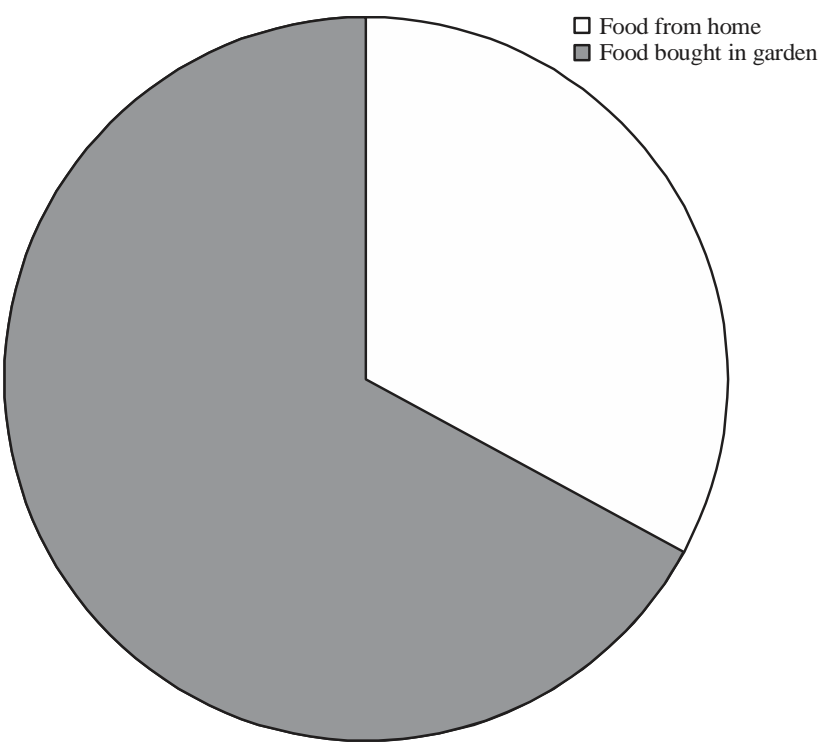

Fig. 3: Proportions of visitors interviewed who brought food from home or bought in the garden

Table 4: Types of precaution methods used by zookeepers

\begin{tabular}{|c|c|c|c|c|c|c|}
\hline \multirow{3}{*}{$\begin{array}{l}\text { Type of } \\
\text { precautions taken }\end{array}$} & \multicolumn{6}{|c|}{ Number of workers involved } \\
\hline & \multicolumn{2}{|c|}{ Male (\%) } & \multicolumn{2}{|c|}{ Female (\%) } & \multicolumn{2}{|c|}{ Total (\%) } \\
\hline & No. & $\%$ & No. & $\%$ & No. & $\%$ \\
\hline Use of gloves & 3 & 21.43 & 2 & 18.18 & 5 & 20 \\
\hline Protective clothing & 10 & 71.43 & 10 & 90.91 & 20 & 80 \\
\hline Avoiding contact with animal & 5 & 35.71 & 2 & 18.18 & 7 & 28 \\
\hline
\end{tabular}

Table 5: Cleaning practices by zookeepers

\begin{tabular}{lcc}
\hline Description & $\begin{array}{c}\text { Number of } \\
\text { practising Keepers }\end{array}$ & \begin{tabular}{c} 
Percentage \\
\hline Cleaning
\end{tabular} \\
Post feeding cleaning & 22 & 88 \\
Disposal of food remains & 24 & 96 \\
Hand washing & & 32 \\
Use of water only & 8 & 56 \\
Use of soap and water & 14 & 12 \\
Use of sanitizers & 3 & 0 \\
Use of wipes only & 0 & \\
\hline
\end{tabular}

food/drinks, 64 (63.4\%) washed their hands before eating while 37 (36.6\%) ate with unwashed hands. Also 51 (50.5\%) visitors washed their hands with water only after eating, $42(41.6 \%)$ visitors used soap in washing their hands only, $4(4 \%)$ of the respondents used wipes while another $4(4 \%)$ respondents used sanitizers (Fig. 5).

Table 6 shows various activities carried out by the 125 participants while in the zoological garden. About $63(50.4 \%)$ of the visitors touched animal cages, $82(65.6 \%)$ ate in the garden, 25 (20\%) fed animals, 44 (35.2\%) played in the playing ground and 7 (5.6\%) picked things from the soil. 


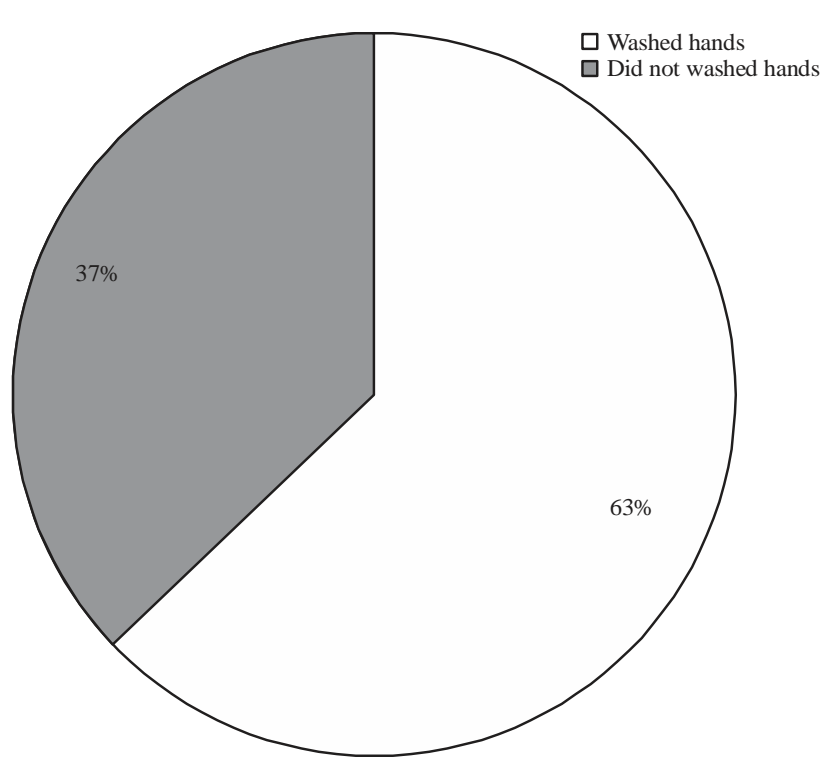

Fig. 4: Percentage of visitors that either washed their hands or did not before eating

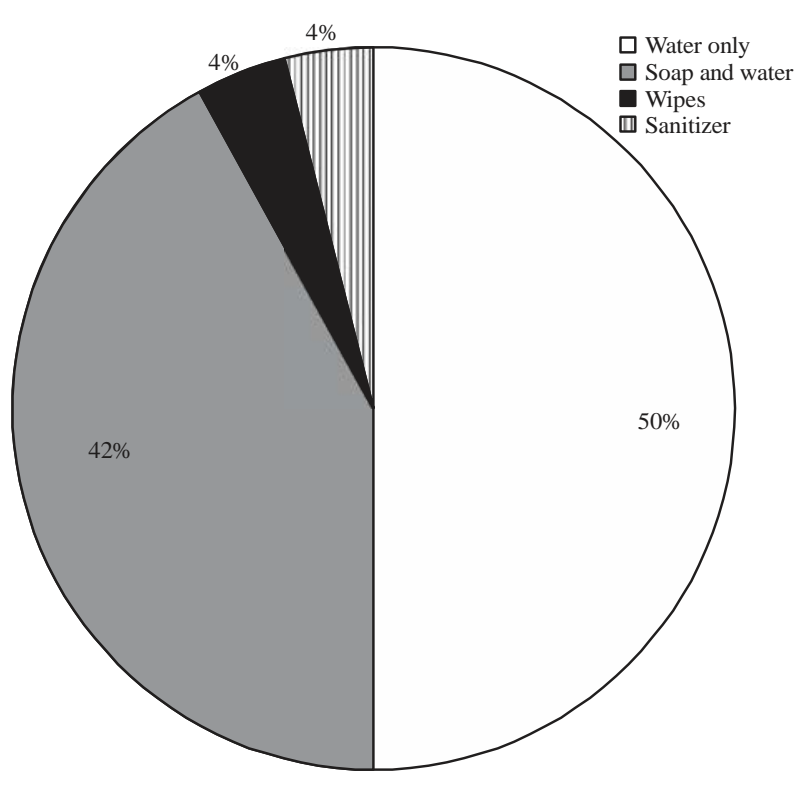

Fig. 5: Hand washing methods used by zoo visitors

Table 7 and 8 show hand washing habits of the study participants in relation to age factor. A significantly higher proportion claimed to wash hand before eating however there was association between age and hand washing while in the zoo $(p=0.080)$. Furthermore, the highest population of respondents rinse hand with water only followed by those who wash with water and soap while the least were those who use wipes and sanitizers (Table 8). The chi-square statistical analysis test showed no association between age categories and nature of cleaning. About 35 out of 57 (61.4\%)
Table 6: Proportion of people involved in different types of risk parameters in the garden

\begin{tabular}{lcc}
\hline Type of action & Number of people & Percentage \\
\hline Touching cages & 63 & 50.4 \\
Eating & 82 & 65.6 \\
Feeding the animals & 25 & 20 \\
Playing in the play ground & 44 & 35.2 \\
Picking from the soil & 7 & 5.6 \\
\hline
\end{tabular}

Table 7: Hand washing before eating in relation to age

\begin{tabular}{lcll}
\hline & & Hand washing before eating \\
Age category & Number examined & Yes (\%) & No (\%) \\
\hline 12 and below & 57 & $35(61.4)$ & $22(38.6)$ \\
$13-19$ & 19 & $16(84.2)$ & $3(15.8)$ \\
20 and above & 25 & $13(52)$ & $12(48)$ \\
Total & 101 & $64(63.4)$ & $37(36.6)$ \\
$\mathrm{p}=0.080$ & & & \\
\hline
\end{tabular}

Table 8: Age in relation to different hand washing methods

\begin{tabular}{llcccc}
\hline & Nature of cleaning & & & & \\
& - & & & & \\
& Rinse with & Wash with soap & Use of & Use of & \\
Age category & water only & and water & wipes & sanitizers & Total \\
\hline 12 and below & $33(57.9 \%)$ & $22(38.6 \%)$ & $2(3.5 \%)$ & $0(0 \%)$ & 57 \\
$13-19$ & $6(31.6 \%)$ & $10(52.3 \%)$ & $1(2.8 \%)$ & $2(10.5 \%)$ & 19 \\
20 and above & $12(48 \%)$ & $10(40 \%)$ & $1(4 \%)$ & $2(8 \%)$ & 25 \\
Total & $51(50.5 \%)$ & $42(41.6 \%)$ & $4(4 \%)$ & $4(4 \%)$ & 101 \\
$p=0.227$ & & & & & \\
\hline
\end{tabular}

in age 12 years and lower clean hands compare to only 16 out of 19 (84.2\%) and 13 out of $25(52 \%)$ in age groups $13-19$ years and 20 years and above who wash hand before eating.

\section{DISCUSSION}

The present study to explore prevalence, intensity and risk factors for STH infection in the Zoological Garden showed a very high prevalence of STH (98.7\%) which implies that there is a higher chance of being exposed to parasites within the garden. This did not come as a surprise since previous studies have shown that captive wild animals harbour parasites some of which are of zoonotic importance ${ }^{6,7}$.

Ascaris has the highest prevalence of $82.7 \%$ among the STHs found in the garden as also recorded by Tefera et al. ${ }^{17}$. The high prevalence of Ascaris can be due to high resistant nature of the egg, Ascaris egg have been found to embryonate under the most adverse environmental condition it can survive in the presence of some chemicals known to be lethal to other parasites eggs. The resistant capacity is conferred by the ascarocide nature of the egg shell which makes egg to remain viable in the soil for several years. 
The highest mean intensity of hookworm observed in the study might be because of the ideal environmental conditions for the survival and development of infective stages such as moist soils this may be attributed to the rainy season when this study was conducted as earlier explained by Nwosu ${ }^{18}$ who documented an increase in hookworm transmission during the rainy season. Trichuris was not found at all during study which is in line with reports of studies carried out by Adefioye et al. ${ }^{19}$.

Also from the different locations in the Zoological Garden where samples were collected, the dumping site 2 which is the main dump site where all wastes (Food), animal faeces from all sections in the garden are dumped had the highest intensity for STH. A recent study also recorded higher intensity of STH in dumpsite ${ }^{20}$.

The fact that the zookeepers' demonstrated adequate hand washing habits as the majority used soap and water showed a low risk of acquiring any possible zoonotic infection in the garden. Females were found to have better hand washing habits than their male counterparts indicating a lower risk among females than male counterparts. Zookeepers because of the activities they carry out in the garden like cleaning, feeding animals) are prone to be exposed to parasites, the survey revealed that a precaution taken by zookeepers as they carry out their activities was not up to standards. Investigations also showed that visitors were allowed to bring food into the garden which further shows a high level risk of exposure to infective parasitic agents while in the garden.

Moreover, majority of visitors (80.8\%) eat in the garden and about $67 \%$ bought the food in the garden this shows that the visitors have a high chance of being infected by the soil transmitted helminths because the food/drink they took have a high chance of being contaminated since they were sold in the Zoological Garden. With the result observations made, it can be concluded that the hand washing behaviour of the visitors were good. Only a few who ate with unwashed hands and participated in one activities or the other a risk factor for the transmission of the parasites had the chance of being infected by STH. Even though, the most effective means of hand washing was not adopted, that is the use of sanitizers.

Activities carried out by the visitors varies but the most frequent activity carried out was touching of cages (50.4\%) and eating (65.6\%) these implies that more than half of the Zoo Visitors has higher chances of been exposed to STH in the zoological garden, owing to the fact that a good number of them bought food from the garden and the most effective method of hand washing was used by a few. Rules guiding human activities in animal settings frown at eating or selling food in such places. Zoos are seen as tourist centers hence the attitude of visitors with access to food in the garden is contrary to standard practices. Age group did not affect the hand washing behaviour of individuals may be because both children and adult exhibit the same hand washing habits were in fun seeking mood and got carried away.

Sanitation and hygiene practices play a key role in the transmission of STH, according to findings by Odinaka et al..$^{21}$ that showed that good hygienic practices and sanitation can reduce the risk of transmission of STH. The hand washing habits displayed by visitors did not meet standard sanitation practices. Even though a higher percentage washed their hands, only few made use of sanitizers. All visitors were involved in one activity or the other that increases the chances of being exposed to STHs.

\section{CONCLUSION}

Zoos are a part of recreational centers. They are known for their aesthetic and educational values, ecological values and conservation values, hence their importance to humans. But the fact remains that zoological gardens are potential risk for transmission of infections of zoonotic importance therefore the need for zoos to provide facilities that will encourage standard hygiene practices by zookeepers and visitors in the Zoo. Also visitors can be enlightened on reasons why some activities should be avoided in the zoological garden, this can be done by the use of billboards placed at strategic places within the garden. Eating in the garden should be discouraged or certain places can be separated for the purpose of eating and this place should be equipped with hand washing facilities and possibly food arenas should be netted.

\section{ACKNOWLEDGMENTS}

Author appreciate the Management and Staff of Zoological Garden for helping with samples collection. Gratitude also goes to the laboratory staff of Parasitology Unit, Department of Zoology, University of Ibadan.

\section{REFERENCES}

1. Collender, P.A., A.E. Kirby, D.G. Addiss, M.C. Freeman and J.V. Remais, 2015. Methods for quantification of soil-transmitted helminths in environmental media: Current techniques and recent advances. Trends Parasitol., 31 : 625-639.

2. Pullan, R.L., J.L. Smith, R. Jasrasaria and S.J. Brooker, 2014. Global numbers of infection and disease burden of soil transmitted helminth infections in 2010. Parasites Vectors, Vol. 7. 10.1186/1756-3305-7-37. 
3. Crompton, D.W.T. and M.C. Nesheim, 2002. Nutritional impact of intestinal Helminthiasis during the human life cycle. Annu. Rev. Nutr., 22: 35-59.

4. Aniwada, E.C., N.D. Uleanya, L.N. Igbokwe and C. Onwasigwe, 2016. transmitted helminths; prevalence, perception and determinants among primary school children in rural Enugu state, Nigeria. Int. J. Trop. Dis. Health, 15: 1-12.

5. Nooraldeen, K., 2015. Contamination of public squares and parks with parasites in Erbil city, Iraq. Ann. Agric. Environ. Med., 22: 418-420.

6. Cordon, G.P., A.H. Prados, D. Romero, M.S. Moreno, A. Pontes, A. Osuna and M.J. Rosales, 2008. Intestinal parasitism in the animals of the zoological garden "Peña Escrita" (Almuñecar, Spain). Vet. Parasitol., 156: 302-309.

7. Tavalla, M., H. Oormazdi, L. Akhlaghi, E. Razmjou and M.M. Lakeh et al., 2012. Prevalence of parasites in soil samples in Tehran public places. Afr. J. Biotechnol., 11: 4575-4578.

8. Mbaya, A.W. and U.J. Udendeye, 2011. Gastrointestinal parasites of captive and free-roaming primates at the Afi mountain primate conservation area in Calabar, Nigeria and their zoonotic implications. Pak. J. Biol. Sci., 14: 709-714.

9. Bethony, J., S. Brooker, M. Albonico, S.M. Geiger, A. Loukas, D. Diemert and P.J. Hotez, 2006. Soil-transmitted helminth infections: Ascariasis, trichuriasis and hookworm. Lancet, 367: 1521-1532.

10. Areola, O., 1994. The Spatial Growth of Ibadan City and its Impact on the Rural Hinterland. In: Ibadan Region, Filani, M.O., F.O. Akintola and C.O. Ikporukpo (Eds.). Rex Charles Publication, Ibadan, Nigeria, pp: 99.

11. Tamuno, T.N., 1981. Ibadan Voices: Ibadan University in Transition. Ibadan University Press, Ibadan, Nigeria, ISBN-13: 9789781211096, Pages: 409.

12. Glenn, I.D., 1992. Determinig sample size. Fact Sheet PEOD-6, November 1992, Florida Cooperative Extension Service, Institute of Food and Agricultural Sciences, University of Florida, USA.
13. Hernandez-Chavarria, F. and L. Avendano, 2001. A simple modification of the Baermann method for diagnosis of strongyloidiasis. Mem. Inst. Oswaldo Cruz, 96: 805-807.

14. Oyebamiji, D.A., A.N. Ebisike, J.O. Egede and A.A. Hassan, 2018. Knowledge, attitude and practice with respect to soil contamination by Soil-Transmitted Helminths in Ibadan, Southwestern Nigeria. Parasite Epidemiol. Control, Vol. 3, No. 4. 10.1016/j.parepi.2018.e00075.

15. Timothy, A., W.J. Reuben, J.B. Abdulhadi and J.A. Mohammed, 2014. A comparative study on the prevalence of intestinal helminthes among rural and sub-urban pupils in Gwagwada, Nigeria. Niger. J. Parasitol. Vect. Biol., 6: 87-91.

16. Rai, S.K., S. Uga, N. Kataoka and T. Matsumura, 1997. Atlas of Medical Parasitology. Kobe University School of Medicine, Kobe, Japan.

17. Tefera, E., T. Belay, S.K. Mekonnen, A. Zeynudin and T. Belachew, 2017. Prevalence and intensity of soil transmitted helminths among school children of Mendera Elementary School, Jimma, Southwest Ethiopia. Pan Afr. Med. J., Vol. 27. 10.11604/pamj.2017.27.88.8817.

18. Nwosu, A.B.C., 1981. The community ecology of soil-transmitted helminth infections of humans in a hyperendemic area of Southern Nigeria. Ann. Trop. Med. Parasitol., 75: 197-203.

19. Adefioye, O.A., A.M. Efunshile, O. Ojurongbe, A.A. Akindele and I.K. Adewuyi et al., 2011. Intestinal helminthiasis among school children in Ilie, Osun State, Southwest, Nigeria. Sierra Leone J. Biomed. Res., 3: 36-42.

20. Ikpeama, C.A., I.O.C. Obiajuru and A.I. Ogomaka, 2016. The impact of refuse disposal dump sites on the spread of intestinal helminthiasis in Owerri metropolis, IMO State, South Eastern Nigeria. Int. J. Clin. Chem. Lab. Med., 2: 13-18.

21. Odinaka, K.K., E.C. Nwolisa, F. Mbanefo, A.C. Iheakaram and S. Okolo, 2015. Prevalence and pattern of soil-transmitted helminthic infection among primary school children in a rural community in Imo State, Nigeria. J. Trop. Med., Vol. 2015. 10.1155/2015/349439. 